\title{
Regulation of extinction of cocaine-induced place preference by midkine is related to a differential phosphorylation of peroxiredoxin 6 in dorsal striatum
}

Esther Gramage $^{\mathrm{a}, \mathrm{b}}$, Carmen Pérez-García ${ }^{\mathrm{a}}$, Marta Vicente-Rodríguez ${ }^{\mathrm{a}}$, Silke Bollen ${ }^{\mathrm{a}}$, Loreto Rojo ${ }^{\text {a }}$ Gonzalo Herradón ${ }^{\text {a,* }}$

aPharmacology lab, Department of Pharmaceutical and Food Sciences. Facultad de Farmacia. Universidad CEU San Pablo, Madrid, Spain.

bPresent address: Department of Ophthalmology and Visual Sciences, W. K. Kellogg Eye Center, University of Michigan, Ann Arbor, MI, USA

*Corresponding author:

Gonzalo Herradon, $\mathrm{PhD}$

Lab. Pharmacology

Faculty of Pharmacy

Universidad CEU San Pablo

Urb. Montepríncipe

28668 Boadilla del Monte, Madrid, Spain.

Tel: 34-91-3724700 (Ext. 4840)

Fax: 34-91-3510475

e-mail: herradon@ceu.es 


\section{ABSTRACT}

The neurotrophic factors Midkine (MK) and Pleiotrophin (PTN) have been suggested to modulate drugs of abuse-induced effects. To test this hypothesis, cocaine (10 and 15 $\mathrm{mg} / \mathrm{kg}$ )-induced conditioned place preference (CPP) was rendered in PTN knockout (PTN-/-), MK knockout (MK-/-) and wild type (WT+/+) mice, and then extinguished after repeated saline injections (distributed in 4 extinction sessions). Cocaine induced a similar CPP in all the three genotypes. We found a significantly increased percentage of MK-/- mice that did not extinguish cocaine CPP at the end of the extinction sessions. Particularly, $40 \%$ of MK-/- mice did not extinguish cocaine $(15 \mathrm{mg} / \mathrm{kg})$-induced CPP compared to $\mathrm{WT}+/+$ and PTN-/- mice $(\sim 0-6 \%)$. Interestingly, we found that a greater magnitude of extinction of CPP after the first extinction session (5 days after last administration of cocaine) correlates with increased tyrosine phosphorylation of the enzyme peroxiredoxin 6 in the dorsal striatum of MK-/- mice. On the other hand, a greater magnitude of CPP extinction correlates with increased tyrosine phosphorylation of aconitase 2 in the prefrontal cortex of $\mathrm{WT}+/+$ mice. In contrast, a lower magnitude of CPP extinction correlates with increased phosphorylation of aconitase 2 in the prefrontal cortex of PTN-/- mice, suggesting that the correlation between the tyrosine phosphorylation levels of aconitase 2 and magnitude of CPP extinction depends on the genotype considered. The data demonstrate that MK is a novel genetic factor that plays a role in the extinction of cocaine-induced CPP by mechanisms that may involve specific phosphorylation of striatal peroxiredoxin 6 .

Keywords: Pleiotrophin, aconitase, conditioned place preference, prefrontal cortex, addiction, amphetamine. 


\section{INTRODUCTION}

Drug addiction is a long lasting and difficult-to-extinct disorder [1], [2] and [3], because memories of the learned association between cues and the rewarding properties of drugs are difficult to extinguish and significantly contribute to drug relapse [4]. The persistent nature of drug addiction suggests that repeated exposure to drugs lead to stable alterations in gene expression or transcription of specific factors that may underlie the individuals' differences in the vulnerability to the addictive effects of drugs [5] and [6].

Environmental cues previously associated with reinforcing drugs can play important parts in drug seeking behaviours in humans [7]. This conditioning in which previous cues acquire secondary reinforcing properties when paired with a primary reinforcer can be tested in the Conditioned Place Preference (CPP) paradigm [8] and [9], which is being increasingly used to study neuroadaptations and to identify novel genetic factors possibly underlying the induction and extinction of drug seeking behaviours, particularly in genetically modified mouse models [9].

Two recently identified genetic factors that are regulated in different brain areas after administrations of different drugs of abuse are pleiotrophin (PTN) and midkine (MK) [10]. PTN and MK are highly redundant in function cytokines [11], [12] and [3], survival factors for dopaminergic neurons and capable to induce the differentiation of stem cells to dopaminergic neurons [14] and [15]. PTN and MK are highly upregulated in different brain areas relevant to drug addiction such as hippocampus, striatum, cingulate cortex, fronto-parietal cortex and prefrontal cortex after administrations of different drugs like nicotine, amphetamine, cannabis, alcohol and morphine [16], [17], [18], [19] and [20], suggesting that MK and PTN could regulate drugs of abuse-induced neuroadaptations and pharmacological effects [21]. This hypothesis has been supported 
by recent findings that uncovered increased neurotoxic effects of amphetamine in the dorsal striatum of PTN genetically deficient (PTN-/-) and MK genetically deficient (MK-/-) mice [22], [23] and [24]. However, it is important to note that dorsal striatum is also an area known to critically contribute to the rewarding properties of psychostimulants such as cocaine in cue-controlled forms of addictive behaviour after extensive drug taking experience [25] and limited drug taking experience [26]. Taking together, the evidence strongly suggests that regulation of striatal levels of PTN and/or MK after administration of drugs of abuse (e.g. amphetamine, see [19]) may serve to modulate drug-induced addictive behaviour. Accordingly, it has been observed that amphetamine-induced conditioning effects were maintained longer in PTN-/- mice [11], [22] and [27]. Whether or not these preliminary studies could be extended to other drugs, would involve MK as well, or would be confirmed in more challenging CPP extinction procedures remained to be studied.

To dissect the possible roles of PTN and MK in the modulation of cocaine rewarding effects we have used PTN-/- and MK-/- mice to perform a CPP paradigm in which a biased apparatus and subject assignment was used. For this purpose, we have tested the acquisition and extinction of cocaine-induced CPP in PTN-/- and MK-/- mice compared to wild type (WT $+/+$, control) mice. Both PTN and MK are ligands of Receptor Protein Tyrosine Phosphatase (RPTP) $\beta / \zeta$ known to inhibit the intrinsic phosphatase activity of this receptor causing as a result a significant increase of the tyrosine phosphorylation levels of a wide variety of proteins [14], a mechanism that seems to underlie many of the known effects of both cytokines [10]. Thus, we have now tested the possible correlation between magnitude of CPP extinction and levels of the phosphoproteins peroxiredoxin 6 and aconitase 2 in dorsal striatum and prefrontal cortex of mice from the three genotypes, since both proteins have been found 
differentially regulated in the striatum of PTN-/- and MK-/- after cocaine administration in previous phosphoproteomics studies [28]. Furthermore, regulators of the enzymatic activity of aconitase 2 have been suggested to play significant roles in the extinction of cocaine-induced CPP in rats [29], whereas other members of the peroxiredoxin family have been found to be differentially regulated in the nucleus accumbens of rhesus monkeys following cocaine self-administration [30] and to be involved in the extinction of cocaine-induced CPP [29]. 


\section{MATERIAL AND METHODS}

\subsection{Pleiotrophin genetically deficient (PTN-/-) and Midkine genetically deficient (MK-/-) mice}

MK-/- and PTN-/- mice on a C57BL/6J background, generated by methods essentially identical to those previously described [31] and [32] were kindly donated by Dr. Thomas F. Deuel (The Scripps Research Institute, La Jolla, CA). We used male PTN-/-, MK-/- and WT+/+ animals of 9-10 weeks (20-25 g). The animals were housed under controlled environmental conditions (22 $\pm 1{ }^{\circ} \mathrm{C}$ and a $12-\mathrm{h}$ light/12-h dark cycle) with free access to food and water. Relevant to the studies presented here, it is important to note that previous behavioural studies have demonstrated the absence of alterations in motor activity, exploration [21] and [22], anxiety or cognition [33] in both knockout mice compared to $\mathrm{WT}+/+$ mice.

All the animals used in this study were maintained in accordance with the European Union Laboratory Animal Care Rules (86/609/ECC directive) and the protocols were approved by the Animal Research Committee of USP-CEU.

\subsection{Conditioned Place Preference (CPP)}

\subsubsection{Apparatus}

The apparatus used consisted of two Plexiglas square compartments of the same size (20 cm long x $14 \mathrm{~cm}$ high x $27 \mathrm{~cm}$ wide). One compartment had black plexiglas floor and walls and the other had black plexiglas floor and white walls. During the cocaine- and saline-paired sessions, the compartments were closed by a removable guillotine door. 


\subsubsection{CPP procedure}

The procedure selected for this study was based on a modification of the method previously used in our laboratory [34].

\subsubsection{Induction of $C P P$}

The procedure to evaluate cocaine-induced conditioning consisted of a 5-day schedule with three phases: preconditioning (Pre-C, day 1), conditioning (days 2-4) and testing (CPP, day 5). During preconditioning, mice were free to explore the two compartments for a 30-min period; their behaviour was monitored by a videotracking system (San Diego, California, USA) to calculate the time spent in each compartment. Placement was counterbalanced within each treatment group such that half the animals started in one chamber and half started in the other. In previous experiments, we previously used this 'biased apparatus and subject assignment, i.e., mice were paired with the drug in the non-preferred compartment, to study genotype differences in amphetamine-induced CPP [21] [22] and [27]. Confirming those studies, the compartment with white walls in the present work was the least-preferred compartment by the three mouse genotypes ( $30 \%$ stay of total time in the preconditioning phase).

In experiments to evaluate cocaine-induced CPP, we performed a short conditioning phase routinely used by our group to describe drugs conditioning effects in rodents [34] that consisted of a 3-day schedule of double conditioning sessions. The first one involved a morning session starting at $8 \mathrm{am}$, in which animals received a single injection of saline i.p. $(10 \mathrm{ml} / \mathrm{kg})$ and were immediately confined to the initially preferred compartment for $30 \mathrm{~min}$. In the evening session starting at $3 \mathrm{pm}$, the animals were injected (i.p.) with $10 \mathrm{mg} / \mathrm{kg}(\mathrm{WT}+/+, \mathrm{n}=14$; PTN-/-, $\mathrm{n}=19$; MK-/-, $\mathrm{n}=20$ ) or 
$15 \mathrm{mg} / \mathrm{kg}(\mathrm{WT}+/+, \mathrm{n}=21 ; \mathrm{PTN}-/-, \mathrm{n}=22 ; \mathrm{MK}-/-, \mathrm{n}=19)$ cocaine $\mathrm{HCl}$ (Alcaliber, Madrid, Spain) and confined to the initially least-preferred compartment for $30 \mathrm{~min}$. On the following two days, the procedure used was the same but the order of the treatments (morning/evening) was changed to avoid the influence of circadian variability (see schematic representation of this procedure in figure 1). In control experiments, mice received injections of saline i.p. (10 $\mathrm{ml} / \mathrm{kg}$ ) at both times (morning/evening) during the three days of the conditioning phase (WT+/+, $\mathrm{n}=6$; PTN-/-, $\mathrm{n}=9$; MK-/-, $\mathrm{n}=7$ ). The doses of cocaine were chosen because they were proved to be effective in the induction of CPP and relevant in similar studies addressing the extinction of cocaine CPP in mice [35] and [36].

The testing phase was carried out on the day 5 of the schedule. In this phase the animals freely moved throughout the apparatus for $30 \mathrm{~min}$, exactly as in the preconditioning phase (day 1). The time spent in each compartment was also registered. The percentage of time-spent (stay) in the least-preferred compartment was then calculated in all cases and the difference between the time spent in this (drug-paired) compartment in this phase (day 5, CPP) and the time spent in the same compartment in the preconditioning (day 1, Pre-C) was considered as indicative of the degree of conditioning induced by cocaine.

\subsubsection{Extinction of cocaine-induced CPP}

The extinction procedure of this study consisted of several sessions as outlined in figure 1. Following the acquisition of CPP (day 5) extinction sessions began. Mice from all genotypes that showed less than $10 \%$ increase in the percentage of stay in the cocaine-paired compartment in day 5 compared to day 1 were considered to have failed to acquire CPP and were excluded of extinction sessions. In the morning of day 6 , mice 
received a single injection of saline i.p. $(10 \mathrm{ml} / \mathrm{kg})$ and were immediately confined to the saline-paired compartment for $30 \mathrm{~min}$. In the evening, the animals were injected (i.p.) with saline again and confined to the cocaine-paired compartment for $30 \mathrm{~min}$. On the following two days, the procedure used was the same but the order of the compartments (morning/evening) was changed as in the conditioning phase. This 3-day extinction session (day 6 through 8) was followed by 2-day extinction sessions in session 2 (days 10 and 11), session 3 (days 13 and 14) and session 4 (days 16 and 17). The day after each extinction session (days 9, 12, 15 and 18), mice were tested in the

CPP apparatus for $30 \mathrm{~min}$, as in day 1 (Pre-C). Animals that returned to baseline behaviour (\% stay in the cocaine-paired compartment as in Pre-C phase $\pm 5 \%$ ) in each one of the extinction sessions (days 9, 12, 15 and 18) were considered to have extinguished cocaine-induced CPP and were removed from the CPP study. In the case of $15 \mathrm{mg} / \mathrm{kg}$ cocaine, after the first extinction session (day 9), animals that returned to baseline behaviour were immediately sacrificed and dorsal striatum and prefrontal cortex were dissected from their brains for subsequent protein analysis.

\subsection{Protein studies}

In previous phosphoproteomics studies from our group similar to those reported with amphetamine [33], we uncovered 7 phosphoproteins differentially expressed in the striatum of PTN-/-, MK-/- and WT+/+ mice treated with a single dose of cocaine (15 $\mathrm{mg} / \mathrm{kg}$ ) [28]. Among these proteins, we selected peroxiredoxin 6 and aconitase 2 to study the possible correlation between the levels of phosphorylation in tyrosine, as well as total levels of these proteins tested in Western blots, and the magnitude of CPP extinction of individuals from every genotype that extinguished cocaine $(15 \mathrm{mg} / \mathrm{kg})$ induced CPP on day 9 (Ext 1). The magnitude of CPP extinction was calculated based 
on the percentage of stay of every mouse in the cocaine $(15 \mathrm{mg} / \mathrm{kg})$-paired compartment in day 5 (CPP) and in day 9 (Ext 1) by means of the formula: CPP (\% stay in drugpaired compartment on day 5) - Ext 1 (\% stay in drug-paired compartment on day 9).

\subsubsection{Western blots}

The levels of phosphorylation in tyrosine as well as total protein levels of aconitase 2 and peroxiredoxin 6 were determined in Western blots following nearly identical protocols to those recently published [33]. Dorsal striatum and prefrontal cortex samples $(n=6-8 /$ experimental group) obtained as indicated in 2.2.2.2 were homogenized in RIPA buffer and protein extracted in presence of protease inhibitors and a phosphatase inhibitor cocktail (Sigma, Madrid, Spain). Total protein was quantified by the Bradford protein assay (Pierce, Rockford, IL, USA). Equilibrated protein samples were mixed with loading buffer (60mM Tris $\mathrm{pH}$ 6.8, 10\% glycerol, 5\% SDS, $0.65 \% \beta$-mercaptoethanol, and $0.01 \%$ bromophenol blue), boiled for 5 minutes, and loaded onto $10 \%$ polyacrylamide gels as appropriate. The gels were transferred to nitrocellulose membranes that were blocked with $50 \mathrm{mM}$ Tris, $150 \mathrm{mM} \mathrm{NaCl}, 0.1 \%$ Tween-20 (TBS-T) and 5\% non-fat milk for 1 hour, and then probed with anti-phosphoTyr (1:1,000) antibodies (Cell signaling, Danvers, MA, USA). Membranes were then re-probed with anti-aconitase 2 (1:1,000) antibodies (Cell signaling, Danvers, MA, USA) or anti-Peroxiredoxin $6(1: 1,000)$ antibodies (Cell signaling, Danvers, MA, USA) to confirm the identity of the protein and to normalize the levels of tyrosine phosphorylation by the content of the target proteins in each of the individual samples. In order to normalize total protein levels of each of these proteins, membranes were reprobed with anti-actin antibodies at a 1:2,000 dilution (Chemicon, Temecula, CA, USA). After 3 washes in TBS-T, the membranes were incubated with appropriate 
secondary antibodies conjugated with horseradish peroxidase diluted 1:5,000 in TBS-T with 5\% non-fat milk for $30 \mathrm{~min}$. The membranes were washed 3 times in TBS-T and the immunoreactive proteins were visualized using the ECL Prime method according to the manufacturer's instructions (Amersham, San Francisco, CA, USA). Phospho-Tyr levels were quantified by densitometry in each animal sample using Image Lab image acquisition and analysis software (Bio-Rad, Hercules, CA, USA) and normalized with total aconitase 2 and peroxiredoxin 6 protein levels.

\subsection{Statistics}

CPP data are represented as the mean \pm SEM of the percentage of stay in the drug-paired compartment before and after the induction of CPP. Following statistical analysis previously used to define the relevance of the data of similar CPP procedures dealing with induction and extinction of cocaine-induced CPP in mice [37], the results were analyzed by a paired 2-tail student's t-test. Contingency tables were built for analysis of data in which the outcome of the experiment were categorical variables (animals from each genotype that were efficiently conditioned or not, and that extinguished or did not extinguish CPP). In these cases, data were analysed by chi square test. The correlation between the magnitude of CPP extinction on day 9 (Ext 1) and the tyrosine phosphorylation levels or total protein levels of peroxiredoxin 6 and aconitase 2 is represented by regression analysis and statistically tested by Pearson correlation coefficient (r).

A p value less than 0.05 was considered a statistically significant difference. All statistical analyses were performed using Graphpad prism 5 program (La Jolla, CA, USA). 


\section{RESULTS}

\subsection{Conditioned Place Preference}

The administration of cocaine (10 and $15 \mathrm{mg} / \mathrm{kg}$ ) during the conditioning phase resulted in acquisition of cocaine-induced CPP in PTN-/-, MK-/- and WT+/+ mice (Figs 2A, 2B, 2C). Saline injections alone did not produce any significant change in compartment preference (Figs 2A, 2B, 2C). The percentage of mice that were not efficiently conditioned by cocaine (mice that did not show a $10 \%$ or higher increase in the percentage of stay in the drug-paired compartment in day 5 compared to day 1) differed between genotypes in the case of the lower dose of cocaine tested (Fig. 3A). The induction of CPP by $10 \mathrm{mg} / \mathrm{kg}$ cocaine was significantly observed in more MK-/mice (90\% of the animals that started in the Pre-C phase) than $\mathrm{WT}+/+$ mice $(57.1 \%)$ (Fig. 3A). However, in the case of the higher dose of cocaine tested, the percentage of mice that acquired cocaine $(15 \mathrm{mg} / \mathrm{kg})$-induced CPP was not significantly different between genotypes (Fig. 3B).

After day 5 of the procedure, mice from the 3 genotypes that failed to acquire CPP were excluded of the subsequent extinction analysis. Thus, mice from all genotypes that remained at the beginning of extinction studies had showed a robust and similar cocaine-induced CPP (day 5) at both doses of the drug tested (Fig. 3C, 3D, 3E). The percentage of mice that extinguished cocaine $(10 \mathrm{mg} / \mathrm{kg})$-induced CPP during the four consecutive extinction sessions was found to be similar in PTN-/- and WT+/+ mice (Figs. 4A, 4B). In contrast, MK-/- mice that did not extinguish cocaine (10 mg/kg)induced CPP by extinction session 1 (mainly) and 2, did not achieve extinction of the CPP at the end of the whole procedure. Although statistical differences were not 
achieved, it has to be noted that $33.3 \%$ of $\mathrm{MK}-/-$ mice that were efficiently conditioned with $10 \mathrm{mg} / \mathrm{kg}$ cocaine in day 5 did not extinguish cocaine-induced CPP by the end of extinction session 4 compared to $15.4 \%$ PTN-/- and $12.5 \%$ WT+/+ mice (Figs. 4A, 4B).

The assays testing the CPP induced by a higher dose of cocaine $(15 \mathrm{mg} / \mathrm{kg})$ rendered significant results. Mice from the 3 genotypes that were efficiently conditioned by cocaine on day $5(\mathrm{WT}+/+, \mathrm{n}=13 ; \mathrm{PTN}-/-, \mathrm{n}=17$; MK-/-, $\mathrm{n}=15)$ entered the extinction sessions. The percentage of mice that extinguished cocaine $(15 \mathrm{mg} / \mathrm{kg})-$ induced CPP at the end of each extinction session was found to be similar in PTN-/- and WT+/+ mice (Figs. 5A, 5B). Interestingly, the differences observed between genotypes in the extinction of cocaine $(10 \mathrm{mg} / \mathrm{kg}$ )-induced CPP (Fig. 4) were found to be exacerbated when testing a higher dose of the drug $(15 \mathrm{mg} / \mathrm{kg})$. In this manner, a significantly increased percentage of MK-/- mice (40\%) did not extinguish cocaineinduced CPP by the end of extinction session 4 compared to 5.8\% PTN-/- mice, whereas all $\mathrm{WT}+/+$ mice extinguished cocaine-induced CPP by the end of session 3 (Figs. 5A, 5B).

\subsection{Peroxiredoxin 6 and aconitase 2 levels in dorsal striatum and prefrontal} cortex of PTN-/-, MK-/- and WT+/+ mice.

First, it has to be noted that the mean of the magnitude of CPP extinction (\% of stay in least-preferred compartment in CPP (day 5) - Ext1) of the PTN-/-, MK-/- and WT+/+ mice that extinguished cocaine $(15 \mathrm{mg} / \mathrm{kg}$ )-induced CPP on day 9 (Ext 1$)$ was found to be similar in all genotypes (Fig $6 \mathrm{~A}-\mathrm{F}$; WT $+/+=44.5 \pm 8.3$, PTN-/- $=43.4 \pm 5.6$, MK-/$=46.7 \pm 11.3$ ). We only found a significant positive correlation between the magnitude of CPP extinction of MK-/- mice and the levels of phosphorylation in tyrosine of peroxiredoxin 6 in the dorsal striatum of MK-/- mice (Fig. 6E). We did not find any 
significant correlation between the total protein levels of peroxiredoxin 6 and the magnitude of CPP extinction in none of the genotypes (Fig. 6B,D,F). In addition, we did not find any significant correlation when considering the levels of phosphorylation or total levels of expression of peroxiredoxin 6 in prefrontal cortex (results not shown).

In contrast, we did not find any significant correlation between the magnitude of CPP extinction and the levels of phosphorylation in tyrosine or the total protein levels of aconitase 2 in the dorsal striatum from PTN-/-, MK-/- and WT+/+ mice (data not shown). However, we found a significant positive correlation between the magnitude of CPP extinction of $\mathrm{WT}+/+$ mice and the levels of phosphorylation in tyrosine of aconitase 2, as well as with total protein levels of aconitase 2, in the prefrontal cortex of $\mathrm{WT}+/+$ mice (Fig. 7A,B). We also found a trend of positive correlation $(\mathrm{r}=0.74, \mathrm{P}=$ 0.094) between the magnitude of CPP extinction of MK-/- mice and the levels of phosphorylation in tyrosine of aconitase 2 in the prefrontal cortex of MK-/- mice (Fig. 7E). In contrast, we observed a significant negative correlation between the magnitude of CPP extinction of PTN-/- mice and the levels of phosphorylation in tyrosine of aconitase 2 in the prefrontal cortex of PTN-/- mice (Fig. 7C) whereas no correlation with the total protein levels of aconitase 2 was observed in this genotype (Fig. 7D). 


\section{DISCUSSION}

In the present work, we have used the CPP paradigm to establish the acquisition and extinction of cocaine-induced CPP in PTN-/-, MK-/- and WT+/+ mice. We found that cocaine induced a similar CPP in all the 3 genotypes although the percentage of MK-/- mice that were efficiently conditioned was significantly higher than that of $\mathrm{WT}+/+$ mice at the lowest dose tested of cocaine $(10 \mathrm{mg} / \mathrm{kg})$, suggesting that genetic deletion of MK may increase the individual vulnerability to cocaine conditioning effects. However, the major finding of the present study is that endogenous MK plays a role in the extinction of cocaine-induced CPP. A significant percentage (40\%) of MK-/mice conditioned with $15 \mathrm{mg} / \mathrm{kg}$ cocaine did not extinguish CPP at the end of the 4 consecutive extinction sessions compared to the modest numbers of PTN-/- and WT+/+ mice that did not extinguish cocaine-induced CPP (5.8 and 0.0\%, respectively). A similar trend was observed with $10 \mathrm{mg} / \mathrm{kg}$ cocaine. Since mice from the 3 genotypes that failed to acquire efficiently cocaine-induced CPP were not used in the extinction procedures and all mice from the 3 genotypes that started the extinction sessions had shown a similar cocaine-induced CPP, genotypic differences in the extinction sessions are not likely to be influenced by differences in the acquisition of cocaine-induced CPP. Also, it is important to note that Nakamura and colleagues [32] showed that the performance of 8 weeks old MK-/- mice in the Y-maze test is similar to that of $\mathrm{WT}+/+$ mice, suggesting that genotypic differences in extinction of cocaine-induced CPP are not related to an enhanced working memory of MK-/- mice compared to control, $\mathrm{WT}+/+$ mice. The data demonstrate that endogenous MK plays a role in the extinction of cocaine-induced CPP. 
It is important to note that the rewarding properties of drugs can be tested in animal models by self-administration studies and the place-conditioning paradigm. CPP is a simple non-invasive procedure which is compatible with the Pavlovian conditioning serving the drug as an unconditioned stimulus that is repeatedly paired with a specific environment that serves as conditioned stimulus. The use of a biased design per se is feasible in place conditioning studies and the outcome can be interpreted in terms of rewarding drug effects, as long as an absolute preference for the drug-paired compartment is produced as in the present work [9]. Although we cannot discount the possibility of a conditioned reduction in aversion to the non-preferred compartment due to possible anxiolytic effects of the drug, the data presented here more likely reflect the rewarding effects of cocaine in our CPP paradigm. In addition, it was previously demonstrated that CPP is also a robust paradigm to study the extinction of drug conditioning effects by repeated pairing of the animals with a saline injection in the previously drug-paired compartment [37] and [38]. Thus, the drug-induced CPP is thought to be relevant to human drug-seeking behaviour following exposure to cues previously associated with drug use [9] [39] and [40].

It is interesting to note that PTN was previously shown to prevent cognitive deficits induced by periadolescent admininstrations of amphetamine [41], to prevent long lasting conditioning effects of amphetamine [22] and to significantly limit amphetamine neurotoxic effects in the substantia nigra and striatum [23]. Interestingly, MK was shown to prevent some of the amphetamine-induced neurotoxic effects in the striatum without exerting important actions on amphetamine conditioning effects [21]. This evidence together with the data presented here support further studies of the PTN and MK signaling pathways in an effort to evaluate their potential for development of effective treatment strategies for drug addiction since these greatly depend on an 
understanding of mechanisms underlying the acquisition and extinction of drug-induced behaviours.

Previous studies demonstrated that one of the mechanisms of action of PTN and MK is through their high affinity interaction with the receptor these cytokines share, the Receptor Protein Tyrosine Phosphatase (RPTP) $\beta / \zeta$ [14]. The interaction of RPTP $\beta / \zeta$ with PTN inactivates the intrinsic tyrosine phosphatase activity of $\mathrm{RPTP} \beta / \zeta$ leaving unchecked the constitutive activity of different protein tyrosine kinases which target the same sites in the substrates of RPTP $\beta / \zeta$ that normally are dephosphorylated by RPTP $\beta / \zeta$ [42] and [43]. Because of this mechanism of action of PTN/MK, we have recently tested the striatal phosphoproteome of PTN-/-, MK-/- and WT+/+ mice 24 hours after treatment with a single dose of cocaine $(15 \mathrm{mg} / \mathrm{kg}$, i.p. $)$ [28]. In this study, in a similar manner to studies recently reported by our group with amphetamine [33], we used a proteomic approach in which we combined phosphoprotein enrichment, by immobilized metal affinity chromatography, with two-dimensional gel electrophoresis and mass spectrometry to finally identify 7 differentially expressed phosphoproteins including peroxiredoxin 6 and aconitase 2 .

In the present studies, we uncover that a greater magnitude of CPP extinction, as measured after the first extinction session of our protocol, correlates in a very specific manner with increased phosphorylation of peroxiredoxin 6 in the dorsal striatum of MK-/- mice. Peroxiredoxin represents a family of sulfhydryl-dependent peroxidases with well-established peroxide-scavenging activity and neuroprotective effects in different neurological disorders [44]. Interestingly, the levels of expression of peroxiredoxin 2 and peroxiredoxin 5 in the nucleus accumbens have been shown to be differentially regulated in rats that extinguish and rats that do not extinguish cocaineinduced CPP [29]. Furthermore, peroxiredoxin 2 is significantly upregulated in the 
nucleus accumbens of rhesus monkeys following cocaine self-administration [30]. To the best of our knowledge, the present data are the first to relate extinction of cocaineinduced CPP and the levels of phosphorylation in tyrosine of peroxiredoxin 6 , a protein that, in addition to play important roles in antioxidant defense it is also important in phospholipid homeostasis [45]. This may be very important since the enzymatic activity of peroxiredoxin 6 seems to significantly depend on specific phosphorylation of its residues [46]. Taking together, our data suggest that MK is a novel genetic factor that regulates the extinction of cocaine-induced CPP by mechanisms that may involve specific phosphorylation of striatal peroxiredoxin 6 . On the other hand, we found that a greater magnitude of CPP extinction significantly correlates with increased phosphorylation of aconitase 2 and total protein levels of aconitase 2 in the prefrontal cortex of $\mathrm{WT}+/+$ mice. Aconitase 2 is an enzyme that catalyses the stereo-specific isomerization of citrate to isocitrate in the tricarboxylic acid cycle [47]. The present data relate, for the first time, extinction of cocaine-induced CPP and the levels of phosphorylation in tyrosine of aconitase 2. Fumarate hydratase, an enzyme that activates aconitase 2 [48], was also one of the few proteins whose levels of expression in the nucleus accumbens differed between rats that extinguish and rats that do not extinguish cocaine-induced CPP [29], supporting a possible role of aconitase 2 in extinction of cocaine CPP. The data obtained in normal mice suggest that increased phosphorylation levels and total protein levels of aconitase 2 in prefrontal cortex is related to the capability of $\mathrm{WT}+/+$ mice to extinguish cocaine-induced CPP. In contrast, a lower magnitude of CPP extinction significantly correlates with increased phosphorylation of aconitase 2 in the prefrontal cortex of PTN-/- mice, suggesting that the correlation between the tyrosine phosphorylation levels of aconitase 2 and magnitude of CPP extinction strongly depends on the genotype considered. 
Conclusion. The data demonstrate that $\mathrm{MK}$ is a novel genetic factor that plays a role in the extinction of cocaine-induced CPP by mechanisms that may involve specific phosphorylation of striatal peroxiredoxin 6 . Further studies are needed to evaluate the specific contribution of phosphorylation of aconitase 2 in prefrontal cortex to extinction of cocaine-induced CPP in WT+/+, PTN-/- and MK-/- mice. 
Acknowledgements: This work has been supported by grants SAF2007-61528 and SAF2009-08136 from Ministerio de Ciencia e Innovación of Spain to GH. EG was supported by fellowship AP2008-00726 from the Spanish Ministerio de Educación. MV-R is supported by fellowship from the Fundación Universitaria San Pablo CEU. LR is a student from University of Surrey supported by the Erasmus Program. 


\section{REFERENCES}

[1] Hyman SE, Malenka RC, Nestler EJ. Neural mechanisms of addiction: the role of reward-related learning and memory. Annu Rev Neurosci 2006; 29:565-598.

[2] Kong $\mathrm{H}, \mathrm{Xu} \mathrm{M}$. Exploring mechanisms underlying extinction of cue-elicited cocaine seeking. Curr Neuropharmacol 2011; 9:8-11.

[3] Nestler EJ. Molecular basis of long-term plasticity underlying addiction. Nat Rev Neurosci 2011; 2:119-128.

[4] O'Brien CP, Childress AR, Ehrman R, Robbins SJ. Conditioning factors in drug abuse: can they explain compulsion? J Psychopharmacol 1998; 12:15-22.

[5] Gorwood P, Le Strat Y, Ramoz N, Dubertret C, Moalic JM, Simonneau M. Genetics of dopamine receptors and drug addiction. Hum Genet 2012; 131:803-822.

[6] Kalivas PW, O'Brien C. Drug addiction as a pathology of staged neuroplasticity. Neuropsychopharmacology 2008; 33:166-180.

[7] Dackis C, O'Brien C. Neurobiology of addiction: treatment and public policy ramifications. Nat Neurosci 2005; 8:1431-1436.

[8] Bardo MT, Bevins RA. Conditioned place preference: what does it add to our preclinical understanding of drug reward? Psychopharmacology 2000; 153:31-43.

[9] Tzschentke TM. Measuring reward with the conditioned place preference (CPP) paradigm: update of the last decade. Addict Biol 2007; 12:227-462.

[10] Herradon G, Ezquerra L, Gramage E, Alguacil LF. Targeting the pleiotrophin/receptor protein tyrosine phosphatase beta/zeta signaling pathway to limit neurotoxicity induced by drug abuse. Mini Rev Med Chem 2009; 9:440-447.

[11] Herradon G, Ezquerra L, Nguyen T, Silos-Santiago I, Deuel TF. Midkine regulates pleiotrophin organ-specific gene expression: evidence for transcriptional regulation and functional redundancy within the pleiotrophin/midkine developmental gene family. Biochem Biophys Res Commun 2005; 333:714-721.

[12] Kadomatsu K, Tomomura M, Muramatsu T. cDNA cloning and sequencing of a new gene intensely expressed in early differentiation stages of embryonal carcinoma cells and in mid-gestation period of mouse embryogenesis. Biochem Biophys Res Commun 1988; 151:1312-1318.

[13] Milner PG, Li YS, Hoffman RM, Kodner CM, Siegel NR, Deuel TF. A novel 17 $\mathrm{kD}$ heparin-binding growth factor (HBGF-8) in bovine uterus: purification and $\mathrm{N}$ terminal amino acid sequence. Biochem Biophys Res Commun 1989; 165:1096-1103.

[14] Herradon G, Ezquerra L. Blocking receptor protein tyrosine phosphatase beta/zeta: a potential therapeutic strategy for Parkinson's disease. Curr Med Chem 2009; 16:33223329. 
[15] Muramatsu T. Midkine: a promising molecule for drug development to treat diseases of the central nervous system. Curr Pharm Des 2011; 17:410-423.

[16] Ezquerra L, Pérez-García C, Garrido E, Díez-Fernández C, Deuel TF, Alguacil LF, Herradón G. Morphine and yohimbine regulate midkine gene expression in the rat hippocampus. Eur J Pharmacol 2007; 557:147-150.

[17] Flatscher-Bader T, Wilce PA. Chronic smoking and alcoholism change expression of selective genes in the human prefrontal cortex. Alcohol Clin Exp Res 2006; 30:908915.

[18] Flatscher-Bader T, Wilce PA. Impact of alcohol abuse on protein expression of midkine and excitatory amino acid transporter 1 in the human prefrontal cortex. Alcohol Clin Exp Res 2008; 32:1849-1858.

[19] Le Grevès P. Pleiotrophin gene transcription in the rat nucleus accumbens is stimulated by an acute dose of amphetamine. Brain Res Bull 2005; 65:529-532.

[20] Mailleux P, Preud'homme X, Albala N, Vanderwinden JM, Vanderhaeghen JJ. Delta-9-Tetrahydrocannabinol regulates gene expression of the growth factor pleiotrophin in the forebrain. Neurosci Lett 1994; 175:25-27.

[21] Gramage E, Martin YB, Ramanah P, Perez-Garcia C, Herradon G. Midkine regulates amphetamine-induced astrocytosis in striatum but has no effects on amphetamine-induced striatal dopaminergic denervation and addictive effects: Functional differences between pleiotrophin and midkine. Neuroscience 2011; 190: 307-317.

[22] Gramage E, Putelli A, Polanco MJ, Gonzalez-Martin C, Ezquerra L, Alguacil LF, Pérez-Pinera P, Deuel TF, Herradon G. The neurotrophic factor pleiotrophin modulates amphetamine-seeking behaviour and amphetamine-induced neurotoxic effects: evidence from pleiotrophin knockout mice. Addict Biol 2010; 15:403-412.

[23] Gramage E, Rossi L, Granado N, Moratalla R, Herradón G. Genetic inactivation of Pleiotrophin triggers amphetamine-induced cell loss in the substantia nigra and enhances amphetamine neurotoxicity in the striatum. Neurosci 2010; 170:308-316.

[24] Gramage E, Herradon G. Connecting Parkinson's disease and drug addiction: common players reveal unexpected disease connections and novel therapeutic approaches. Curr Pharm Des 2011; 17:449-461.

[25] Pierce RC, Vanderschuren LJ. Kicking the habit: the neural basis of ingrained behaviors in cocaine addiction. Neurosci Biobehav Rev 2010; 35:212-9.

[26] Veeneman MM, Broekhoven MH, Damsteegt R, Vanderschuren LJ. Distinct contributions of dopamine in the dorsolateral striatum and nucleus accumbens shell to the reinforcing properties of cocaine. Neuropsychopharmacology 2012; 37:487-98. 
[27] Martín YB, Gramage E, Herradón, G. Maintenance of amphetamine-induced place preference does not correlate with astrocytosis. Eur J Pharmacol 2013; 699:258-63.

[28] Gramage E, Vicente-Rodríguez M, Herradón G \& Pérez-García C (2013). Differential phosphoproteome of the striatum from pleiotrophin knockout and midkine knockout mice treated with cocaine. Neuroscience Meeting Planner. San Diego, LA: Society for Neuroscience, 2013 (accepted).

[29] Del Castillo C, Morales L, Alguacil LF, Salas E, Garrido E, Alonso E, PérezGarcía C. Proteomic analysis of the nucleus accumbens of rats with different vulnerability to cocaine addiction. Neuropharmacology 2009; 57:41-8.

[30] Tannu NS, Howell LL, Hemby SE. Integrative proteomic analysis of the nucleus accumbens in rhesus monkeys following cocaine self-administration. Mol Psychiatry 2010; 15:185-203.

[31] Amet LE, Lauri SE, Hienola A, Croll SD, Lu Y, Levorse JM, Prabhakaran B, Taira T, Rauvala H, Vogt TF. Enhanced hippocampal long-term potentiation in mice lacking heparin-binding growth-associated molecule. Mol Cell Neurosci 2001; 17:1014-1024.

[32] Nakamura E, Kadomatsu K, Yuasa S, Muramatsu H, Mamiya T, Nabeshima T, Fan QW, Ishiguro K, Igakura T, Matsubara S, Kaname T, Horiba M, Saito H, Muramatsu T. Disruption of the midkine gene (Mdk) resulted in altered expression of a calcium binding protein in the hippocampus of infant mice and their abnormal behaviour. Genes Cells 1998; 3:811-822.

[33] Gramage E, Herradón G, Martín YB, Vicente-Rodríguez M, Rojo L, Gnekow H, Barbero A, Pérez-García C. Differential phosphoproteome of the striatum from pleiotrophin knockout and midkine knockout mice treated with amphetamine: Correlations with amphetamine-induced neurotoxicity. Toxicology 2013; 306:147-56.

[34] Morales L, Perez-Garcia C, Herradon G, Alguacil LF. Place conditioning in a twoor three-conditioning compartment apparatus: a comparative study with morphine and U-50,488. Addict Biol 2007; 12: 482-484.

[35] Miller LL, Ward SJ, Dykstra LA. Chronic unpredictable stress enhances cocaineconditioned place preference in type 1 cannabinoid receptor knockout mice. Behav Pharmacol 2008; 19:575-581.

[36] Vranjkovic O, Hang S, Baker DA, Mantsch JR. Beta adrenergic receptor mediation of stress-induced reinstatement of extinguished cocaine-induced conditioned place preference in mice: roles for beta- 1 and beta-2 adrenergic receptors. J Pharmacol Exp Ther 2012; 342:541-51.

[37] Itzhak Y, Martin JL. Cocaine-induced conditioned place preference in mice: induction, extinction and reinstatement by related psychostimulants. Neuropsychopharmacology 2002; 26:130-134.

[38] Mueller D, Stewart J. Cocaine-induced conditioned place preference: reinstatement by priming injections of cocaine after extinction. Behav Brain Res 2000; 115:39-47. 
[39] O'Brien CP, Childress AR, McLellan T, Ehrman R. Integrating systemic cue exposure with standard treatment in recovering drug dependent patients. Addict Behav 1990; 15:355-365.

[40] Stewart J, Vezina P. A comparison of the effects of intra-accumbens injections of amphetamine and morphine on reinstatement of heroin intravenous self-administration behavior. Brain Res 1988; 457:287-294.

[41] Gramage E, Del Olmo N, Fole A, Martín YB, Herradón G. Periadolescent amphetamine treatment causes transient cognitive disruptions and long-term changes in hippocampal LTP depending on the endogenous expression of pleiotrophin. Addict Biol 2013; 18:19-29.

[42] Pariser H, Ezquerra L, Herradon G, Perez-Pinera P, Deuel TF. Fyn is a downstream target of the pleiotrophin/receptor protein tyrosine phosphatase beta/zeta-signaling pathway: regulation of tyrosine phosphorylation of Fyn by pleiotrophin. Biochem Biophys Res Commun 2005; 332:664-669.

[43] Martin YB, Herradón G, Ezquerra L. Uncovering new pharmacological targets to treat neuropathic pain by understanding how the organism reacts to nerve injury. Curr Pharm Des 2011; 17:434-448.

[44] Zhu H, Santo A, Li Y. The antioxidant enzyme peroxiredoxin and its protective role in neurological disorders. Exp Biol Med (Maywood) 2012; 237:143-9.

[45] Fisher AB. Peroxiredoxin 6: a bifunctional enzyme with glutathione peroxidase and phospholipase $A_{2}$ activities. Antioxid Redox Signal 2011; 15:831-44.

[46] Rahaman H, Zhou S, Dodia C, Feinstein SI, Huang S, Speicher D, Fisher AB. Increased phospholipase A2 activity with phosphorylation of peroxiredoxin 6 requires a conformational change in the protein. Biochemistry 2012; 51:5521-5530.

[47] Beinert H, Kennedy MC. Aconitase 2, a two-faced protein: enzyme and iron regulatory factor. FASEB J 1993; 7:1442-9.

[48] Ternette N, Yang M, Laroyia M, Kitagawa M, O'Flaherty L, Wolhulter K, Igarashi K, Saito K, Kato K, Fischer R, Berquand A, Kessler BM, Lappin T, Frizzell N, Soga T, Adam J, Pollard PJ. Inhibition of mitochondrial aconitase 2 by succination in fumarate hydratase deficiency. Cell Rep 2013; 3:689-700. 


\section{FIGURE LEGENDS}

Fig 1. Timeline of the study.

Fig. 2. Cocaine-induced place preference. Results are presented as the mean \pm SEM of the percentage of the time spent by WT+/+ (A), PTN-/- (B) and MK-/- (C) mice in the cocaine (10 and $15 \mathrm{mg} / \mathrm{kg}$ )-paired or saline-paired, in the case of the controls, leastpreferred compartments during preconditioning (Pre-C, day 1) and testing phases (CPP, day 5). $* \mathrm{P}<0.05$ vs. Pre-C; $* * \mathrm{P}<0.01$ vs. Pre-C; $* * * \mathrm{P}<0.001$ vs. Pre-C.

Fig. 3. PTN-/-, MK-/- and WT+/+ conditioned with cocaine (10 and $15 \mathrm{mg} / \mathrm{kg})$. Tables represent the number and the percentage of mice from all genotypes that were efficiently conditioned after a short conditioning phase (days 2 to 4) with $10 \mathrm{mg} / \mathrm{kg}$ cocaine (A) and $15 \mathrm{mg} / \mathrm{kg}$ cocaine (B). Results are presented as the mean $\pm \mathrm{SEM}$ of the percentage of the time spent exclusively by the efficiently conditioned WT $+/+(\mathrm{C})$, PTN-/- (D) and MK-/- (E) mice in the cocaine (10 and $15 \mathrm{mg} / \mathrm{kg}$ )-paired (leastpreferred) compartment during preconditioning (Pre-C, day 1) and testing (CPP, day 5) phases. Thus, these data represent those of the experimental groups starting the subsequent extinction sessions. \# $\mathrm{P}<0.05$ vs. WT+/+; ** $\mathrm{P}<0.01$ vs. Pre-C; *** $\mathrm{P}<$ 0.001 vs. Pre-C.

Fig. 4. Extinction of cocaine $(10 \mathrm{mg} / \mathrm{kg})$-induced place preference. The evolution of the percentages of mice from all genotypes that continue without extinguishing (No extinguish, NE) cocaine-induced CPP after each of the 4 extinction phases (Ext 1, day 9; Ext 2, day 12; Ext 3, day 15; Ext 4, day 18) are represented (A). Table represents the 
numbers of mice from the total conditioned mice (n (CPP)) of all genotypes that extinguished cocaine-induced CPP in each extinction phase (B).

Fig. 5. Extinction of cocaine (15 $\mathrm{mg} / \mathrm{kg})$-induced place preference. The evolution of the percentages of mice from all genotypes that continue without extinguishing (No extinguish, NE) cocaine-induced CPP after each of the 4 extinction phases (Ext 1, day 9; Ext 2, day 12; Ext 3, day 15; Ext 4, day 18) are represented (A). Table represents the numbers of mice from the total conditioned mice (n (CPP)) of all genotypes that extinguished cocaine-induced CPP in each extinction phase (B). \# P $<0.05$ vs. WT+/+; \#\# $\mathrm{P}<0.01$ vs. $\mathrm{WT}+/+; \S \mathrm{P}<0.05$ vs. PTN-/-.

Fig. 6. Correlation between the levels of peroxiredoxin 6 in dorsal striatum and the magnitude of CPP extinction of individuals from WT+/+ -, PTN-/- and MK-/- mice that extinguished cocaine-induced CPP on day 9 (Ext 1). The levels of phosphorylation of Tyr and total protein levels of peroxiredoxin 6 (Prdx6) were assessed by western blotting and total protein levels of Prdx6 were normalized to actin. Representative images (two samples from each genotype: WT+/+ (W), PTN-/- (P), MK/- (M)) are shown here. The ratio between the levels of phosphorylation in tyrosine (PTyr) and the total protein levels of Prdx6 is represented vs. the magnitude of CPP extinction (\% of stay in least-preferred compartment in CPP - E1) in WT+/+ (A), PTN/- (C) and MK-/- (E). According to individual $\mathrm{x}$-axis values of graphs $\mathrm{A}, \mathrm{C}$ and $\mathrm{E}$, global genotypic differences in P-Tyr/Prdx6 values are observed $(\mathrm{WT}+/+$ : $0.01 \pm 0.01$; PTN-/-: $0.38 \pm 0.08$; MK-/-: $0.03 \pm 0.01)$. The ratio between the total protein levels of Prdx6 and actin levels is represented vs. the magnitude of CPP extinction (CPP - E1) in $\mathrm{WT}+/+(\mathrm{B}), \mathrm{PTN}-/-(\mathrm{D})$ and MK-/- (F). Again, according to individual $\mathrm{x}$-axis values of 
graphs B, D and F, global genotypic differences in Prdx6/Actin values are observed $(\mathrm{WT}+/+: 0.20 \pm 0.05 ;$ PTN-/-: $0.03 \pm 0.01 ;$ MK-/-: $1.10 \pm 0.30)$. Pearson correlation coefficient and $\mathrm{p}$ value is shown when statistical significance was achieved $(\mathrm{P}<0.05)$.

Fig. 7. Correlation between the levels of aconitase 2 in prefrontal cortex and the magnitude of CPP extinction of individuals from WT+/+ -, PTN-/- and MK-/- mice that extinguished cocaine-induced CPP on day 9 (Ext 1). The levels of phosphorylation of Tyr and total protein levels of aconitase 2 (Aconitase; Aco 2) were assessed by western blotting and total protein levels of Aco 2 were normalized to actin. Representative images (two samples from each genotype: WT+/+ (W), PTN-/- (P), MK/- (M)) are shown here. The ratio between the levels of phosphorylation in tyrosine (PTyr) and the total protein levels of aconitase 2 is represented vs. the magnitude of CPP extinction (\% of stay in least-preferred compartment in CPP - E1) in WT+/+ (A), PTN/- (C) and MK-/- (E). According to individual $\mathrm{x}$-axis values of graphs A, C and E, global genotypic differences in P-Tyr/Aconitase values are observed (WT+/+: $0.20 \pm$ 0.02; PTN-/-: $0.52 \pm 0.12$; MK-/-: $0.18 \pm 0.02$ ). The ratio between the total protein levels of aconitase and actin levels is represented vs. the magnitude of CPP extinction (CPP - E1) in WT+/+ (B), PTN-/- (D) and MK-/- (F). Again, according to individual Xaxis values of graphs $\mathrm{B}, \mathrm{D}$ and $\mathrm{F}$, global genotypic differences in Aconitase/Actin values are observed (WT+/+: $0.25 \pm 0.03$; PTN-/-: $0.48 \pm 0.03$; MK-/-: $0.22 \pm 0.05)$. Pearson correlation coefficient and $\mathrm{p}$ value is shown when statistical significance was achieved $(\mathrm{P}<0.05)$. 